\title{
Risk factors for neurological worsening and symptomatic watershed infarction in internal carotid artery aneurysm treated by extracranial-intracranial bypass using radial artery graft
}

\author{
Hidetoshi Matsukawa, MD,, Rokuya Tanikawa, MD, ${ }^{1}$ Hiroyasu Kamiyama, MD, ${ }^{1}$ \\ Toshiyuki Tsuboi, MD, PhD, ${ }^{1}$ Kosumo Noda, MD, ${ }^{1}$ Nakao Ota, MD, ${ }^{1}$ Shiro Miyata, MD, PhD, ${ }^{1}$ \\ Jumpei Oda, MD, PhD, ${ }^{1}$ Rihee Takeda, MD, ${ }^{1}$ Sadahisa Tokuda, MD, ${ }^{1}$ and \\ Kyousuke Kamada, MD, PhD²
}

'Department of Neurosurgery, Stroke Center, Teishinkai Hospital, Sapporo; and ²Department of Neurosurgery, Asahikawa Medical University, Asahikawa, Japan

OBJECTIVE The revascularization technique, including bypass created using the external carotid artery (ECA), radial artery (RA), and $\mathrm{M}_{2}$ portion of middle cerebral artery (MCA), has remained indispensable for treatment of complex aneurysms. To date, it remains unknown whether diameters of the RA, superficial temporal artery (STA), and $C_{2}$ portion of the internal carotid artery (ICA) and intraoperative MCA blood pressure have influences on the outcome and the symptomatic watershed infarction (WI). The aim of the present study was to evaluate the factors for the symptomatic WI and neurological worsening in patients treated by ECA-RA-M $\mathrm{M}_{2}$ bypass for complex ICA aneurysm with therapeutic ICA occlusion. METHODS The authors measured the sizes of vessels (RA, $C_{2}, M_{2}$, and STA) and intraoperative MCA blood pressure (initial, after ICA occlusion, and after releasing the RA graft bypass) in 37 patients. Symptomatic WI was defined as presence of the following: postoperative new neurological deficits, WI on postoperative diffusion-weighted imaging, and ipsilateral cerebral blood flow reduction on SPECT. Neurological worsening was defined as the increase in 1 or more modified Rankin Scale scores. First, the authors performed receiver operating characteristic curve analysis for continuous variables and the binary end point of the symptomatic WI. The clinical, radiological, and physiological characteristics of patients with and without the symptomatic WI were compared using the log-rank test. Then, the authors compared the variables between patients with and without neurological worsening at discharge and at the 12-month follow-up examination or last hospital visit.

RESULTS Symptomatic WI was observed in $2(5.4 \%)$ patients. The mean MCA pressure after releasing the RA graft $(<55 \mathrm{~mm} \mathrm{Hg} ; p=0.017)$, mean (MCA pressure after releasing the RA graft)/(initial MCA pressure) $(<0.70 \mathrm{~mm} \mathrm{Hg} ; p=$ $0.032)$, and mean cross-sectional area ratio $\left(\left[\mathrm{RA} / \mathrm{C}_{2} \text { diameter }\right]^{2}<0.40 \mathrm{~mm}[\mathrm{p}<0.0001]\right.$ and $\left[\mathrm{STA} / \mathrm{C}_{2} \text { diameter }\right]^{2}<0.044$ $\mathrm{mm}[\mathrm{p}<0.0001])$ were related to the symptomatic WI. All preoperatively independent patients remained independent (modified Rankin Scale score $<3)$. After adjusting for age and sex, left operative side $(p=0.0090$ and 0.038 ) and perforating artery ischemia ( $p=0.0050$ and 0.022 ) were related to neurological worsening at discharge (11 [29\%] patients) and at the 12-month follow-up or last hospital visit (8 [22\%] patients).

CONCLUSIONS Results of the present study showed that the vessel diameter and intraoperative MCA pressure had impacts on the symptomatic WI and that operative side and perforating artery ischemia were related to neurological worsening in patients with complex ICA aneurysms treated by ECA-RA-M $\mathrm{M}_{2}$ bypass.

http://thejns.org/doi/abs/10.3171/2015.5.JNS142524

KEY WORDS EC-IC bypass; neurological worsening; symptomatic watershed infarction; vascular disorders

$\mathrm{T}$ HE negative results of the Carotid Occlusion Surgery Study trial ${ }^{21}$ and the introduction of flow-diverting stents ${ }^{16}$ have resulted in many practitioners rethinking the utility of cerebral revascularization for vascular pa- thologies. However, revascularization techniques remain indispensable because of the need for complex reconstructions when endovascular therapies fail in patients with cerebral aneurysm. In addition, cerebral revascularization

ABBREVIATIONS ECA = external carotid artery; EC-IC = extracranial-intracranial; ICA = internal carotid artery; IQR = interquartile range; $M C A=$ middle cerebral artery; $\mathrm{mRS}=$ modified Rankin Scale; PCoA = posterior communicating artery; RA = radial artery; STA = superficial temporal artery; WI = watershed infarction .

SUBMITTED November 22, 2014. ACCEPTED May 7, 2015.

INCLUDE WHEN CITING Published online November 13, 2015; DOI: 10.3171/2015.5.JNS142524. 
strategies become necessary in select patients whose aneurysms are challenging to treat due to size, shape, location, intramural thrombus, atherosclerotic plaques, aneurysm type, vessels arising from the dome, poor collateral vascularization, or previously coiled thrombosed giant aneurysm when parent artery or branch occlusion is required. ${ }^{18}$ In such situations, vascular reconstruction using extracranial to intracranial (EC-IC) bypass followed by the occlusion of the aneurysm is indicated.

Graft bypass using the radial artery (RA) is promising to replace graft bypass using the internal carotid artery (ICA).$^{17}$ The choice of bypass procedure depends on the amount of flow replacement required, and the size and availability of donor and recipient vessels. Immediate results and management of the bypass ${ }^{13,23,27}$ and clinical follow-up results ${ }^{13,22,24}$ have been reported previously. However, factors related to symptomatic watershed infarction (WI) have not been analyzed. Furthermore, it remains unknown whether diameters of RA, superficial temporal artery (STA) and $\mathrm{C}_{2}$ portion of ICA and intraoperative middle cerebral artery (MCA) blood pressure have influences on the outcome and the symptomatic WI. To our knowledge, this is the first study to evaluate the symptomatic WI; sizes of RA, STA, and $\mathrm{C}_{2}$; and intraoperative MCA blood pressure in patients treated by the external carotid artery (ECA)-RA-M $\mathrm{M}_{2}$ bypass for complex ICA aneurysm with therapeutic ICA occlusion.

\section{Methods}

This study is reported based on criteria from STROBE (Strengthening the Reporting of Observational Study in Epidemiology). ${ }^{29}$ The study protocol was approved by the institutional ethics committee. Between April 2012 and July 2014, 38 patients underwent ECA-RA-M $\mathrm{M}_{2}$ bypass for complex ICA aneurysm at the Department of Neurosurgery at Teishinkai Hospital. Of these, 1 female patient was excluded because she was lost to follow-up. Thus, a total of 37 patients participated in the present study.

\section{Clinical Characteristics}

We collected the following data: age, sex, smoking history, medical history (hypertension, hypercholesterolemia, and diabetes mellitus), preoperative symptoms, size of aneurysm, aneurysm location, operative side, thrombosis or calcification of aneurysm, vessel diameters $\left(\mathrm{RA}, \mathrm{C}_{2}, \mathrm{M}_{2}\right.$, and STA), intraoperative MCA pressure (initial, after ICA occlusion, and after releasing the RA graft bypass), the RA graft blood flow, temporary occlusion time during bypasses, postoperative diffusion-weighted imaging findings, aneurysm recurrence, follow-up duration, graft patency, and outcome.

The RA was evaluated on 3D CT angiography. An Allen test was performed to confirm an intact palmar arch and adequate hand perfusion despite occlusion of the RA. Diameters of RA, STA (branch that was used for STAMCA bypass), $M_{2}$, and $C_{2}$ (when aneurysm was located at $\mathrm{C}_{2}$, we measured the diameter of $\mathrm{C}_{1}$ portion of ICA) were also measured on 3D CT angiography. In reference to Darcy's law ${ }^{3}$ and Hagen-Poiseuille law, 7,20 we used the calculations $\left(\mathrm{RA} / \mathrm{C}_{2}\right.$ diameter) ${ }^{2}$ and $\left(\mathrm{STA} / \mathrm{C}_{2}\right.$ diameter) ${ }^{2}$ to evaluate the cross-sectional area.

\section{Indication and Surgical Technique}

The ECA-RA-M $\mathrm{M}_{2}$ bypass was performed for complex ICA aneurysms for the following indications: aneurysms with a large and complex neck not suitable for clip reconstruction, blister aneurysms, dissecting aneurysms, aneurysms with an origin of branch vessel(s) from the aneurysm sac, calcification or atherosclerotic changes of the neck, extensive thrombosis inside the aneurysm, and recurrent aneurysms for which endovascular or microsurgical treatment had failed. Our policy for these complex aneurysms is first to make an STA-MCA bypass followed by the ECA-RA-M $\mathrm{M}_{2}$ bypass in all cases that potentially need ICA occlusion, regardless of the results of the balloon test occlusion (14 patients underwent balloon test occlusion preoperatively). We have termed this procedure "universal extracranial-intracranial bypass"14 and performed the STA-MCA bypass not only as a backup for clamping of the RA- $\mathrm{M}_{2}$ anastomosis but also to monitor the MCA pressure.

During surgery, patients received total intravenous anesthesia along with somatosensory and motor evoked potential monitoring. The operative techniques of ECARA-M $\mathrm{M}_{2}$ and STA-MCA bypasses have recently been published. ${ }^{13}$ As stated above, the single STA-MCA bypass was performed not only as a backup for clamping of RA graft$\mathrm{M}_{2}$ anastomosis but also to provide a conduit to monitor the MCA blood pressure before and after the ECA-RA- $\mathrm{M}_{2}$ graft bypass. One branch of the STA was anastomosed to the $M_{3}$ or $M_{4}$ portion distal to the recipient $M_{2}$, which is usually the inferior trunk. The other STA branch was immediately connected to the pressure transducer to monitor MCA pressure. Initial MCA pressure, MCA pressure after temporary clamping of the ICA, and MCA pressure after releasing the RA graft bypass were continuously monitored and recorded (Fig. 1). After ECA-RA-M $\mathrm{M}_{2}$ bypass was performed, the RA graft mean blood flow ( $\mathrm{ml} / \mathrm{min})$ was measured by Surgical Flowmeters (Transonic Systems). The temporary clamp was placed on the proximal ICA before opening the RA graft, and the MCA pressure was monitored by applying a temporary clip to the STA trunk. If the graft worked well, decreased MCA pressure immediately recovered upon opening the RA graft. The MCA pressure was continuously monitored until the dura mater was closed and the bone flap was fixed in place. Flow through the bypass was confirmed by ultrasonography with a micro-Doppler probe and indocyanine green videoangiography.

\section{Outcome}

The graft patency was confirmed by CT angiography. Any observed narrowing of $\geq 50 \%$ was considered stenosis. Diffusion-weighted MRI was performed to evaluate ischemic lesions. The diagnosis of WI was established using previously published template. ${ }^{1,4,30}$ The symptomatic WI was defined as the presence of the following: 1) postoperative new neurological deficits; 2) WI on postoperative diffusion-weighted imaging; and 3) ipsilateral cerebral blood flow reduction on SPECT, which was performed in patients with postoperative new neurological deficits. Imaging assessment of patients included combinations of MRI, MR angiography, and CT angiography. Aneurysm treatment failure was defined as posttreatment aneurysm growth or rupture. 


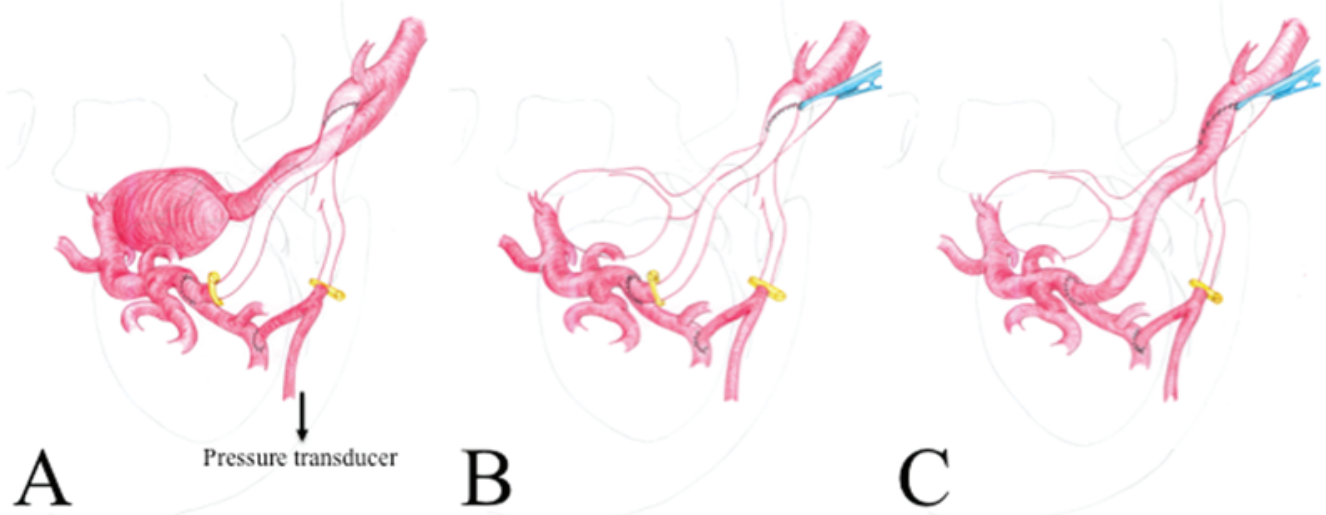

FIG. 1. One branch of the STA was anastomosed to the $M_{3}$ portion distal to the recipient $M_{2}$. The RA graft subsequently was anastomosed to the target $\mathrm{M}_{2}$. A 22-gauge tube was inserted into the other branch of the STA and connected to the pressure transducer to monitor the MCA pressure. Initial MCA pressure (A), MCA pressure after temporary clamping of the ICA (B), and MCA pressure after releasing the RA graft bypass $(\mathrm{C})$ were continuously monitored and recorded. Copyright Jumpei Oda. Published with permission. Figure is available in color online only.

Clinical outcome was examined at discharge and at the 12-month follow-up examination or last hospital visit using a modified Rankin Scale (mRS), ${ }^{28}$ either by telephone interviews (conducted by H.M. independently of the primary surgeon) with the patient or family members or during a physical examination of those who were able to visit our hospital. Neurological worsening was defined as the increase in 1 or more $\mathrm{mRS}$ scores.

\section{Statistical Analysis}

Statistical analysis was performed using SPSS for Mac (version 21.0; SPSS). Variables are expressed as the mean $\pm \mathrm{SD}$, median (interquartile range [IQR] 25th-75th percentile), or number of patients (\%), as appropriate. The chi-square test or Fisher exact test was performed for categorical variables as appropriate. The normality of data was evaluated using the Shapiro-Wilk test. Normally distributed continuous variables were compared using the Student t-test and nonnormally distributed variables were compared using the Mann-Whitney U-test.

First, we performed receiver operating characteristic curve analysis for continuous variables and the binary end point of the symptomatic WI. We selected cut-off points for these variables that optimized sensitivity and specificity. We compared the clinical, radiological, and physiological characteristics of patients with and without the symptomatic WI using the log-rank test. The probability of freedom from the symptomatic WI was estimated using the Kaplan-Meier method; comparisons of the survival curves by the factors, which were related to the symptomatic WI, were performed using the log-rank test. Then, we compared the variables between patients with and without neurological worsening at discharge and at the 12-month follow-up examination or last hospital visit using univariate analysis. Differences were considered significant at $\mathrm{p}<$ 0.05 for a $95 \%$ CI.

\section{Results}

\section{Baseline Characteristics}

The mean age of patients was $62 \pm 10$ years, and 32
(87\%) patients were women. Fourteen (38\%) patients had double vision, 11 (30\%) had minor headache, $4(11 \%)$ had visual field and/or visual acuity abnormality, 4 (11\%) developed postclipping aneurysm regrowth, $3(8.1 \%)$ developed subarachnoid hemorrhage, and 1 (2.7\%), when undergoing diagnostic imaging studies, was diagnosed with spontaneous cerebellar hemorrhage. The mean size of the aneurysms was $18 \pm 8.7 \mathrm{~mm}$. There were $19(51 \%)$ aneurysms on the left side and 18 (49\%) on the right. The aneurysms were located at the $C_{1}(n=7,19 \%), C_{1}-C_{2}(n$ $=3,8.1 \%), C_{2}(n=6,16 \%), C_{2}-C_{3}(n=2,5.4 \%), C_{3}(n=4$, $11 \%), \mathrm{C}_{3}-\mathrm{C}_{4}(\mathrm{n}=2,5.4 \%)$, and $\mathrm{C}_{4}(\mathrm{n}=12,32 \%)$ portions of the ICA and the cervical ICA (dissecting aneurysm, $\mathrm{n}=$ $1,2.7 \%$ ). A calcified aneurysm was seen in $19(51 \%)$ cases and a thrombosed aneurysm in $6(16 \%)$.

\section{Perioperative Findings}

The mean diameters of the RA, STA, recipient $\mathrm{M}_{2}$, and $\mathrm{C}_{2}$ were $3.1 \pm 0.42 \mathrm{~mm}, 1.4 \pm 0.44 \mathrm{~mm}, 2.6 \pm 0.46 \mathrm{~mm}$, and $3.7 \pm 0.49 \mathrm{~mm}$, respectively. The mean $\left(\mathrm{RA} / \mathrm{C}_{2}\right.$ diameter $)^{2}$ and $\left(\mathrm{STA} / \mathrm{C}_{2} \text { diameter }\right)^{2}$ were $0.79 \pm 0.34 \mathrm{~mm}$ and $0.16 \pm 0.098 \mathrm{~mm}$, respectively. The STA-MCA bypass was performed in $36(97 \%)$ patients. The frontal branch of the STA was used in $29(81 \%)$ patients and the parietal branch in $7(19 \%)$ for anastomosis. Because the STA had been sacrificed by previous craniotomy, STA-MCA bypass could not be performed in $1(2.7 \%)$ patient (see Illustrative Case). In this patient, intraoperative MCA pressure was monitored by an interosseous artery, which was harvested during RA exposure and anastomosed with $\mathbf{M}_{3}$. Cervical ICA ligation was performed in $20(54 \%)$ patients and aneurysm trapping in 17 (46\%). The mean initial MCA pressure was $71 \pm 11 \mathrm{~mm} \mathrm{Hg}$, the mean MCA pressure after ICA occlusion was $45 \pm 15 \mathrm{~mm} \mathrm{Hg}$, and the mean MCA pressure after releasing the RA graft bypass was $64 \pm 9.7 \mathrm{~mm} \mathrm{Hg}$. The mean ratio of MCA pressure after releasing the RA graft bypass/initial MCA pressure was $0.89 \pm 0.17 \mathrm{~mm}$ and that of MCA pressure after releasing ICA occlusion/initial MCA pressure was $0.65 \pm 0.22 \mathrm{~mm}$. MCA pressure monitoring detected RA graft kinking in 3 
patients, which led to immediate revisions of the anastomoses during the surgery. The mean temporary occlusion times were $19 \pm 5.7$ minutes for STA-MCA anastomosis and $21 \pm 3.7$ minutes for the RA graft $-\mathrm{M}_{2}$ anastomosis. The mean blood flow of the RA graft was measured in 31 patients; the median RA graft blood flow was $126 \mathrm{ml} / \mathrm{min}$ (IQR $115-197 \mathrm{ml} / \mathrm{min}$ ).

Symptomatic WI was observed in $2(5.4 \%)$ patients. The flow reduction in the affected area on SPECT was larger than in lesions on diffusion-weighted imaging. Symptoms-motor aphasia and motor weakness-occurred 6 and 7 days after surgical procedures. These symptoms completely resolved during the follow-up period. Postoperative diffusion-weighted imaging revealed ischemia in the perforating artery distribution in $7(19 \%)$ patients (anterior thalamoperforating artery distribution in 4 [11\%], basal ganglia in 2 [5.4\%], and internal capsule in 1 [2.7\%]). Among these patients, 4 (11\%) had cognitive dysfunctions, $3(8.1 \%)$ were asymptomatic, $2(5.4 \%)$ had motor aphasia, and $1(2.7 \%)$ had hemiparalysis. These 7 patients had no symptomatic WI. Symptomatic hyperperfusion occurred the day after surgery in $2(5.4 \%)$ patients, who experienced hyperactivity. This symptom also completely resolved within a few days. Postoperative RA graft stenosis (57\% $\pm 6.3 \%$ ) was seen in $5(14 \%)$ patients. It occurred on the ECA-RA bypass side in $2(5.4 \%)$ patients and on the $\mathrm{M}_{2}$ RA bypass side in $3(8.1 \%)$ patients. Although it improved in $4(11 \%)$ patients $2-70$ days after the surgery, RA graft thinning $(2.3-1.7 \mathrm{~mm})$ was observed 53 days after the surgery in $1(2.7 \%)$ patient. This thinning graft was patent during the follow-up period. No patients with postoperative RA graft stenosis had ischemic complications.

The results of analysis of factors related to the symptomatic WI are shown in Table 1. The MCA pressure after releasing the RA graft bypass $(<55 \mathrm{~mm} \mathrm{Hg}$ ); (MCA pressure after releasing the RA graft bypass)/(initial MCA pressure) $(<0.70 \mathrm{~mm} \mathrm{Hg})$; RA diameter $(<2.8 \mathrm{~mm}) ; \mathrm{C}_{2}$ diameter $(<4.4 \mathrm{~mm})$; STA diameter $(<0.8 \mathrm{~mm})$; $\left(\mathrm{RA} / \mathrm{C}_{2}\right.$ diameter $)^{2}(<0.40 \mathrm{~mm})$; and $\left(\mathrm{STA} / \mathrm{C}_{2} \text { diameter }\right)^{2}(<0.044$ $\mathrm{mm}$ ) were significantly related to the symptomatic WI by the log-rank test. Other variables showed no significant difference between patients with and without the symptomatic WI.

\section{Outcome and Follow-Up}

Preoperative, postoperative, and long-term outcomes by $\mathrm{mRS}$ are shown in Table 2 . All preoperatively independent patients remained independent ( $\mathrm{mRS}$ score $<3$ ) at discharge and at the 12-month follow-up or last hospital visit. The results of analysis of factors related to neurological worsening at discharge and at the 12-month follow-up or last hospital visit are shown in Table 3. Left operative side, ischemia in the perforating artery distribution, and the symptomatic WI were significantly related to neurological worsening at discharge. After adjusting for age and sex, left operative side, and ischemia in the perforating artery distribution were still associated with neurological worsening at discharge. Left operative side and ischemia in the perforating artery distribution were also significantly related to neurological worsening at the 12-month follow-up or last hospital visit. After adjusting for age and sex, left operative side, and ischemia in the perforating artery distribution still remained significant. Other variables showed no significant difference between patients with and without neurological worsening.

During a median follow-up period of 7.2 months (range 4.6-12 months), all RA graft bypasses remained patent by serial MRI or 3D/4D CT angiography, and there were no subarachnoid hemorrhages or deaths. Aneurysm regrowth occurred 162 days after surgery in $1(2.7 \%)$ patient. This patient was a 70-year-old woman who had a left cavernous portion giant aneurysm with oculomotor nerve palsy. Initially, she underwent ECA-RA-M ${ }_{2}$ bypass with cervical ICA ligation. Following aneurysm regrowth, she underwent aneurysmal trapping.

\section{Illustrative Case}

A 65-year-old woman was referred to our hospital because of left aneurysm recurrence. Twenty-three years prior, she had undergone aneurysm neck clipping for left ruptured ICA-posterior communicating artery (ICAPCoA) aneurysm and right unruptured ICA-PCoA aneurysm at another hospital. She was examined with MRI and CT angiography, which revealed a large left ICA-PCoA aneurysm $(20 \mathrm{~mm})$ (Fig. 2). The sizes of the left radial artery, $\mathrm{M}_{2}$, and $\mathrm{C}_{2}$ were $2.75 \mathrm{~mm}, 2.49 \mathrm{~mm}$, and $4.20 \mathrm{~mm}$, respectively. We used the left transsylvian approach and observed the large aneurysm. Because the STA had been sacrificed in a previous craniotomy, intraoperative MCA pressure was monitored via an interosseous artery, which was harvested during RA exposure and anastomosed with $\mathrm{M}_{3}$. The mean arterial pressure of the MCA monitored by the interosseous artery, which was $74 \mathrm{~mm} \mathrm{Hg}$ before cervical ICA ligation, fell to $39 \mathrm{~mm} \mathrm{Hg}$ with ICA ligation. It was restored to $52 \mathrm{~mm} \mathrm{Hg}$ after the release of the RA-M ${ }_{2}$ bypass. The left ICA-PCoA aneurysm was surgically trapped. The patient awoke from anesthesia without any neurological deficits. Postoperative CT angiography showed disappearance of the aneurysm and patency of the ECA-RA-M ${ }_{2}$ bypass (Fig. 3A). However, the patient developed motor aphasia and slight hemiparesis on the left side 7 days after surgery. Diffusion-weighted imaging showed high signal intensity lesions in the left anterior watershed territory (Fig. 3B), and SPECT revealed left cerebral blood flow reduction (Fig. 3C). The symptoms completely resolved within a few hours after adequate blood pressure control. She was discharged home with mild diplopia and cognitive dysfunction 6 weeks after the surgery (mRS score 2).

\section{Discussion}

The present study showed that the proportion of vessel diameters used for bypasses and intraoperative MCA pressure were related to the symptomatic WI. In addition, the left operative side and ischemia in the perforating artery distribution were associated with neurological worsening at discharge and at the 12-month follow-up or last hospital visit.

The EC-IC bypass may be required for aneurysms that are complex because of a very broad neck (neck to dome ratio $>2$ ); the absence of a neck, such as in fusiform aneu- 
TABLE 1. Analysis of factors related to symptomatic WI*

\begin{tabular}{|c|c|c|c|}
\hline \multirow[b]{2}{*}{ Variable } & \multicolumn{2}{|c|}{ Symptomatic WI } & \multirow[b]{2}{*}{ p Value } \\
\hline & Yes, $n=2$ & No, $n=35$ & \\
\hline Mean size of aneurysm, mm (SD) & $17(8.8)$ & $18(8.9)$ & \\
\hline$>18.5$ & $1(50)$ & $14(40)$ & 0.77 \\
\hline Postoperative RA graft stenosis & 0 & $5(14)$ & 0.57 \\
\hline Cervical ICA ligation & 0 & $20(57)$ & 0.12 \\
\hline \multicolumn{4}{|l|}{ Mean MCA pressure } \\
\hline Initial, mm Hg (SD) & $75(19)$ & $71(11)$ & \\
\hline$<56$ & $1(50)$ & $3(8.6)$ & 0.052 \\
\hline After ICA occlusion, mm Hg (SD) & $53(23)$ & $44(14)$ & \\
\hline$<41$ & $2(100)$ & $8(23)$ & 0.10 \\
\hline After releasing RA graft bypass, $\mathrm{mm} \mathrm{Hg}(\mathrm{SD})$ & $51(5.1)$ & $65(9.2)$ & \\
\hline$<55 \dagger$ & $2(100)$ & $8(23)$ & 0.017 \\
\hline After releasing/initial, $\mathrm{mm} \mathrm{Hg}(\mathrm{SD})$ & $0.72(0.25)$ & $0.91(0.15)$ & \\
\hline$<0.70 \dagger$ & $2(100)$ & $20(57)$ & 0.032 \\
\hline Initial/clamp, mm Hg (SD) & $0.63(0.15)$ & $0.65(0.22)$ & \\
\hline$<0.73$ & $2(100)$ & $20(57)$ & 0.24 \\
\hline Median, RA graft blood flow, ml/min (IQR) & $209(122-) \ddagger$ & $126(114-192)$ & \\
\hline$<200$ & $1(50)$ & $25(71)$ & 0.16 \\
\hline \multicolumn{4}{|l|}{ Mean vessel diameter } \\
\hline $\mathrm{RA}, \mathrm{mm}(\mathrm{SD})$ & $2.7(0.21)$ & $3.2(0.42)$ & \\
\hline$<2.8 \dagger$ & $2(100)$ & $7(20)$ & 0.010 \\
\hline $\mathrm{C}_{2}, \mathrm{~mm}(\mathrm{SD})$ & $4.5(0.12)$ & $3.6(0.47)$ & \\
\hline$<4.4 \dagger$ & $2(100)$ & 0 & $<0.0001$ \\
\hline $\mathrm{M}_{2}, \mathrm{~mm}(\mathrm{SD})$ & $2.6(0.18)$ & $2.6(0.46)$ & \\
\hline$<2.5$ & $1(50)$ & $20(57)$ & 0.85 \\
\hline STA, mm (SD) & $0.86(1.2)$ & $1.4(0.39)$ & \\
\hline$<0.8 \dagger$ & $1(50)$ & $2(5.7)$ & 0.031 \\
\hline$\left(\mathrm{RA} / \mathrm{C}_{2}\right)^{2}, \mathrm{~mm}(\mathrm{SD})$ & $0.35(0.074)$ & $0.82(0.36)$ & \\
\hline$\left(\mathrm{RA} / \mathrm{C}_{2}\right)^{2}<0.40 \dagger$ & $2(100)$ & $3(8.6)$ & $<0.0001$ \\
\hline$\left(\mathrm{STA} / \mathrm{C}_{2}\right)^{2}, \mathrm{~mm}(\mathrm{SD})$ & $0.076(0.11)$ & $0.17(0.096)$ & \\
\hline$\left(\mathrm{STA} / \mathrm{C}_{2}\right)^{2}<0.044 \dagger$ & $1(50)$ & $2(5.7)$ & 0.031 \\
\hline \multicolumn{4}{|l|}{ Mean temporary occlusion time } \\
\hline STA-MCA, $\min (\mathrm{SD})$ & $16(0.92)$ & $19(5.8)$ & \\
\hline$>16$ & $1(50)$ & $20(57)$ & 0.83 \\
\hline RA-MCA, min (SD) & $17(2.8)$ & $21(3.7)$ & \\
\hline$>20$ & 0 & $18(51)$ & 0.16 \\
\hline
\end{tabular}

rysms or dissecting aneurysms; the presence of severe atherosclerosis or calcification in the neck area; the presence of extensive thrombosis inside the aneurysm; the origin of critical branches from the aneurysm sac or neck; symptomatic dissecting aneurysms; and in cases of small blister aneurysms, which have no neck at all. ${ }^{18}$ The STA-MCA bypass is a convenient procedure but brings limited blood flow, which makes us skeptical regarding its usefulness when the ICA is occluded. ${ }^{12}$ The RA, on the other hand, has a larger diameter and has been used as a graft between the ECA and MCA when a larger amount of blood flow is necessary, e.g., when the ICA is necessarily sacrificed. ${ }^{10,11}$
Based on these studies, our policy regarding these complex aneurysms is first to make a graft bypass with the RA in all cases that potentially need ICA occlusion.

\section{Vessel Diameters}

There are several theoretical reasons for using the RA graft in EC-IC bypass. ${ }^{26}$ The RA is an artery that is physiologically intended to convey arterial flow. The lumen caliber more closely approximates that of the $\mathrm{M}_{2}$ segment, which is the recipient vessel usually used. It has a uniform intimal wall that lacks the valves and varices characteristic of venous grafts. The RA provides a flow 
TABLE 2. Outcomes by mRS score

\begin{tabular}{cc}
\hline mRS Score & No. of Patients $(\%)$ \\
\hline Preoperative & \\
\hline 0 & $12(32)$ \\
\hline 1 & $15(41)$ \\
\hline 2 & $8(22)$ \\
\hline 3 & $1(2.7)$ \\
\hline 4 & $1(2.7)$ \\
\hline At discharge & \\
\hline 0 & $15(41)$ \\
\hline 1 & $7(19)$ \\
\hline 2 & $13(35)$ \\
\hline 3 & $1(2.7)$ \\
\hline 4 & $1(2.7)$ \\
\hline At 12 mos & \\
\hline 0 & $20(54)$ \\
\hline 1 & $9(24)$ \\
\hline 2 & $6(16)$ \\
\hline 3 & $1(2.7)$ \\
\hline 4 & $1(2.7)$ \\
\hline
\end{tabular}

rate between 50 and $150 \mathrm{ml} / \mathrm{min}$ acutely, and the flow can increase significantly over the ensuing days as measured by transcranial Doppler flowmetry. ${ }^{25}$ The size and health of the RA must be evaluated and matched to the need. Although it was thought that the STA should be at least $1 \mathrm{~mm}$ in caliber, an RA should be at least $2.4 \mathrm{~mm}$ and preferably $2.5 \mathrm{~mm}$ or larger at the minimum diameter for ECIC bypass, ${ }^{27}$ and RA grafts can supply enough blood flow volume to perfuse the ipsilateral MCA area, ${ }^{13}$ to date, there have been few studies which have analyzed the relationship between the vessel diameter and the symptomatic WI. In addition, the sizes of the RA and STA vary from patient to patient, and there is no preoperative assurance that the RA and STA can supply enough blood flow to compen- sate for the occluded ICA. ${ }^{9}$ To our knowledge, we showed for the first time that the cross-sectional areas (which were calculated by diameters of RA, $\mathrm{C}_{2}$, and STA) were related to the symptomatic WI. When therapeutic ICA occlusion is planned, evaluation of vessel diameters and calculation of the cross-sectional areas-not the type of graft-should be performed to prevent the symptomatic WI. If preoperative evaluation reveals small cross-sectional ratios, a larger graft, such as the saphenous vein, may have to be used for ECA-M ${ }_{2}$ bypass.

\section{MCA Pressure Monitoring}

Using MCA pressure monitoring, we could detect the perfusion pressure of the MCA territory before, during, and after temporary occlusion. This monitoring was also useful for checking the patency of the graft after the therapeutic ICA occlusion. ${ }^{12}$ Because the RA graft itself is not visible after passing through the route, we have used MCA pressure, in addition to motor or somatosensory evoked potentials, to judge if the graft is working well. In the present study, MCA pressure monitoring also detected RA graft kinking in 3 patients. We revised anastomosis during the surgery in these 3 patients, and they had no symptomatic WI. Although the RA- $\mathrm{M}_{2}$ bypass was shown to be able to maintain the arterial pressure in the MCA territory as high as in the ICA, ${ }^{12}$ values of MCA pressure needed to prevent the cerebral cortical tissue from ischemia remain unknown. To our knowledge, the present study shows for the first time that the values of MCA pressure monitoring, especially MCA pressure after releasing the RA graft bypass of less than $55 \mathrm{~mm} \mathrm{Hg}$ and (MCA pressure after releasing the RA graft bypass)/(initial MCA pressure) of less than $0.70 \mathrm{~mm} \mathrm{Hg}$, were associated with the symptomatic WI. On the other hand, the RA graft blood flow was not associated with the symptomatic WI. We thought that the RA graft blood flow was influenced by the graft kinking and/or distortion, especially on the route from the cranium to the neck, and that it might not reflect the accurate blood flow. Because MCA pressure was measured distal to the RA-M $\mathrm{M}_{2}$ anastomosis, it was more important for evaluat-

TABLE 3. Analysis of factors related to neurological worsening*

\begin{tabular}{|c|c|c|c|c|c|c|c|c|}
\hline \multirow[b]{2}{*}{ Variable } & \multicolumn{2}{|c|}{ NW at Discharge } & \multicolumn{2}{|c|}{$p$ Value } & \multicolumn{2}{|c|}{ NW at 12 Mos } & \multicolumn{2}{|c|}{$p$ Value } \\
\hline & Yes, $n=11$ & No, $n=26$ & Crude & Adjusted & Yes, $n=8$ & No, $n=29$ & Crude & Adjusted \\
\hline Median age, yrs (IQR) & $65(8.5)$ & $60(11)$ & 0.23 & & $65(8.4)$ & $61(11)$ & 0.33 & \\
\hline Sex, F & $10(91)$ & $22(85)$ & 0.61 & & $8(100)$ & $24(83)$ & 0.56 & \\
\hline Postclip regrowth & $1(9.1)$ & $2(7.7)$ & 1.0 & & $1(13)$ & $2(6.9)$ & 0.53 & \\
\hline Op side, left†‡ & $10(91)$ & $17(65)$ & 0.003 & 0.0090 & $7(88)$ & $12(41)$ & 0.042 & 0.038 \\
\hline Postop RA graft stenosis & $3(27)$ & $2(7.7)$ & 0.11 & & $3(38)$ & $2(6.9)$ & 0.057 & \\
\hline Perforator infarction†‡ & $6(55)$ & $1(3.8)$ & 0.01 & 0.0050 & $4(50)$ & $3(10)$ & 0.027 & 0.022 \\
\hline \multicolumn{9}{|c|}{ Temporary occlusion time, mins } \\
\hline STA-MCA & $21(5.8)$ & $18(5.5)$ & 0.24 & & $21(6.4)$ & $18(5.3)$ & 0.17 & \\
\hline RA-MCA & $22(4.5)$ & $21(3.5)$ & 0.62 & & $21(2.8)$ & $21(4.0)$ & 0.80 & \\
\hline Symptomatic WI† & $2(18)$ & 0 & 0.025 & 0.99 & $1(13)$ & $1(3.4)$ & 0.39 & \\
\hline
\end{tabular}

NW = neurological worsening.

* Data are expressed as number of patients (\%), unless otherwise indicated.

$\dagger$ Variables significantly related to NW by univariate analysis.

$\ddagger$ Variables significantly related to NW after adjusting for age and sex. 

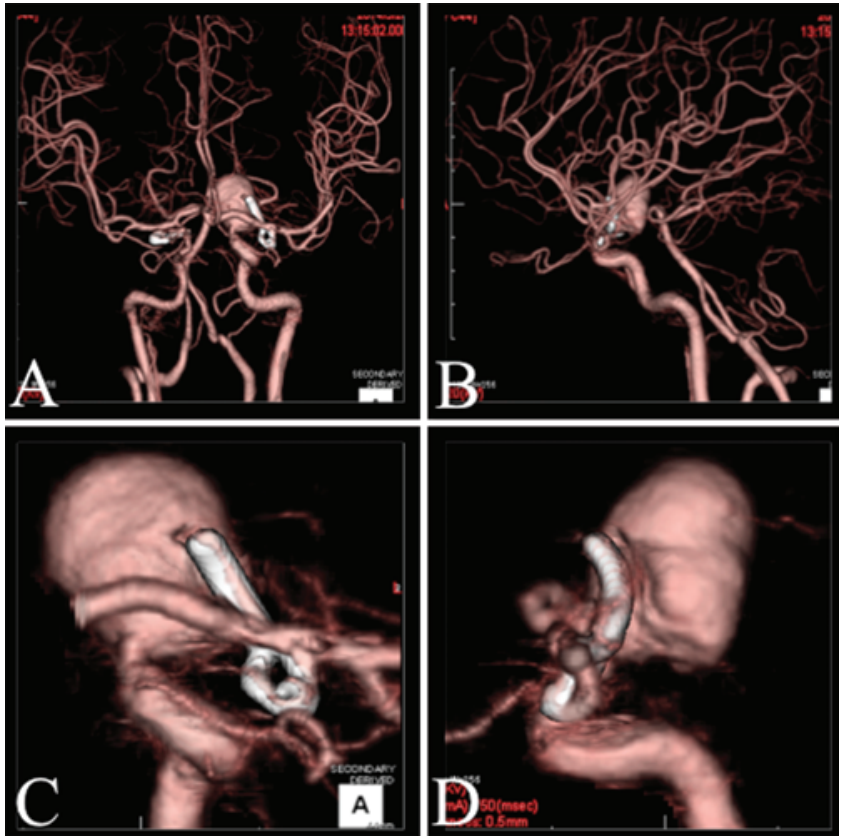

FIG. 2. Anteroposterior ( $A$ and $C$ ) and lateral (B and $D$ ) preoperative 3D CT angiograms showing a recurrent left ICA-PCoA aneurysm and previously applied clips. Figure is available in color online only.

ing the cerebral perfusion (Fig. 1). Furthermore, although MCA pressure monitoring may reflect only the cortical artery perfusion pressure and does not reflect ischemia of the deep cerebral area perfused by the perforating arteries, ${ }^{12}$ we regarded this MCA pressure monitoring as a useful tool for preventing bypass failure during surgery.

\section{Outcome}

All RA grafts were patent in the present study, the results of which are comparable or superior to previous studies. ${ }^{6,13,15,18}$ All preoperatively independent patients remained independent (mRS score $<3$ ) at discharge and at the 12-month follow-up or last hospital visit. However, neurological worsening was observed in $11(29 \%)$ patients at discharge and in 8 (22\%) patients at the 12-month followup or last hospital visit. We observed that left operative side and ischemia in the perforating artery distribution were related to neurological worsening. Therefore, the injury of perforating artery around aneurysm should be avoided in patients with complex ICA aneurysm treated with the ECA-RA-M $\mathrm{M}_{2}$ bypass, especially on the left side.

\section{Limitations}

Our study had a retrospective design, with inherent limitations leading to potential ascertainment bias. In addition, the number of patients was small. Furthermore, because the number of WIs was exceedingly low, it might be difficult to draw conclusions. Although supportive STAMCA anastomosis constructed before the RA graft bypass procedure increases the total time of the operation, it is useful for avoiding major ischemic injury during largecaliber anastomosis ${ }^{2,5,8,19}$ because it is impossible to know how long the recipient $\mathrm{M}_{2}$ can withstand temporary occlu-
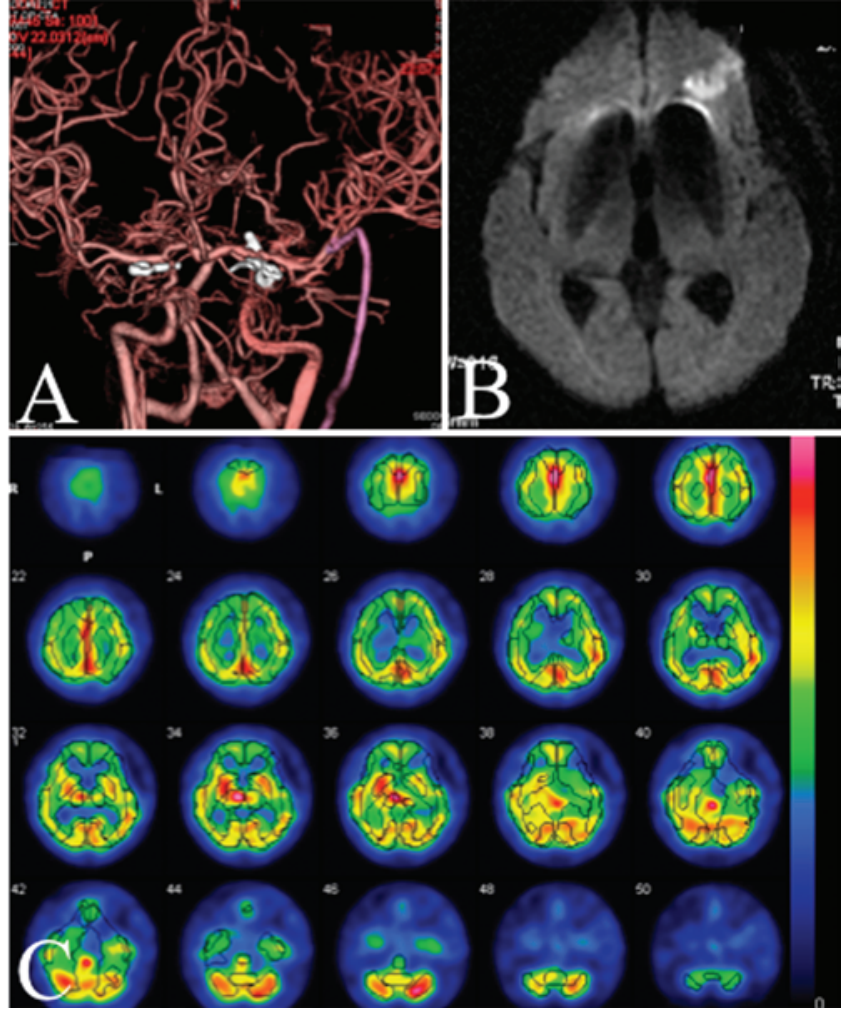

FIG. 3. A: An anteroposterior image of postoperative 3D CT angiography shows disappearance of aneurysm and patency of the ECA-RA-M bypass. B: Diffusion-weighted image showing a lesion with high signal intensity in the left anterior watershed territory. C: Left cerebral blood flow reduction was observed on SPECT. Figure is available in color online only.

sion during the anastomosis. The mean temporary occlusion time was $19 \pm 5.7$ minutes for STA-MCA anastomosis. In addition, whether spasm of the STA or distal MCA branches affected the measurements remains unknown. The results of the present study should be further clarified using an independent cohort.

\section{Conclusions}

The results of the present study showed that the crosssectional area of the vessel diameter used for the bypass and intraoperative MCA pressure had impacts on the symptomatic WI. Also, left operative side and ischemia in the perforating artery distribution were related to neurological worsening in patients with complex ICA aneurysms who were treated by ECA-RA-M $\mathrm{M}_{2}$ bypass.

\section{References}

1. Bogousslavsky J, Regli F: Unilateral watershed cerebral infarcts. Neurology 36:373-377, 1986

2. Chen L, Lang L, Zhou L, Song D, Mao Y: Bypass or not? Adjustment of surgical strategies according to motor evoked potential changes in large middle cerebral artery aneurysm surgery. World Neurosurg 77:398.E1-398.E6, 2012

3. Curry FE: Mechanics and thermodynamics of transcapillary exchange, in Handbook of Physiology: The Cardiovascular System. Bethesda, MD: American Physiological Society, 1984 
4. Damasio H: A computed tomographic guide to the identification of cerebral vascular territories. Arch Neurol 40:138142,1983

5. Ferch R, Pasqualin A, Pinna G, Chioffi F, Bricolo A: Temporary arterial occlusion in the repair of ruptured intracranial aneurysms: an analysis of risk factors for stroke. J Neurosurg 97:836-842, 2002

6. Gobble RM, Hoang H, Jafar J, Adelman M: Extracranialintracranial bypass: resurrection of a nearly extinct operation. J Vasc Surg 56:1303-1307, 2012

7. Hagen CHL: Uber die Bewegung des Wassers in engen cylindrischen Rohren. Annalen der Physik und Chemie 42:423-442, 1839

8. Hongo K, Horiuchi T, Nitta J, Tanaka Y, Tada T, Kobayashi $\mathrm{S}$ : Double-insurance bypass for internal carotid artery aneurysm surgery. Neurosurgery 52:597-602, 2003

9. Houkin K, Ishikawa T, Kuroda S, Abe H: Vascular reconstruction using interposed small vessels. Neurosurgery 43:501-505, 1998

10. Houkin K, Kamiyama H, Kuroda S, Ishikawa T, Takahashi A, Abe $\mathrm{H}$ : Long-term patency of radial artery graft bypass for reconstruction of the internal carotid artery. Technical note. J Neurosurg 90:786-790, 1999

11. Ishikawa T, Kamiyama H, Houkin K, Takahashi A, Iwasaki Y, Abe H: Postsurgical observations of mean hemispheric cerebral blood flow with patients receiving high-flow EC-IC bypass using a radial artery graft (preliminary report, oneyear observation of 10 hemispheres). Surg Neurol 43:500509,1995

12. lshikawa T, Kamiyama H, Kobayashi N, Tanikawa R, Takizawa K, Kazumata K: Experience from "double-insurance bypass." Surgical results and additional techniques to achieve complex aneurysm surgery in a safer manner. Surg Neurol 63:485-490, 2005

13. Ishishita Y, Tanikawa R, Noda K, Kubota H, Izumi N, Katsuno M, et al: Universal extracranial-intracranial graft bypass for large or giant internal carotid aneurysms: techniques and results in 38 consecutive patients. World Neurosurg 82:130-139, 2014

14. Javedan SP, Deshmukh VR, Spetzler RF, Zabramski JM: The role of cerebral revascularization in patients with intracranial aneurysms. Neurosurg Clin N Am 12:541-555, viii, 2001

15. Kalani MY, Ramey W, Albuquerque FC, McDougall CG, Nakaji P, Zabramski JM, et al: Revascularization and aneurysm surgery: techniques, indications, and outcomes in the endovascular era. Neurosurgery 74:482-498, 2014

16. Kallmes DF, Ding YH, Dai D, Kadirvel R, Lewis DA, Cloft HJ: A new endoluminal, flow-disrupting device for treatment of saccular aneurysms. Stroke 38:2346-2352, 2007

17. Kamiyama H: [Bypass with radial artery graft.] No Shinkei Geka 22:911-924, 1994 (Jpn)

18. Mohit AA, Sekhar LN, Natarajan SK, Britz GW, Ghodke B: High-flow bypass grafts in the management of complex intracranial aneurysms. Neurosurgery 60:ONS105-ONS123, 2007

19. Ogilvy CS, Carter BS, Kaplan S, Rich C, Crowell RM: Temporary vessel occlusion for aneurysm surgery: risk factors for stroke in patients protected by induced hypothermia and hypertension and intravenous mannitol administration. $\mathbf{J}$ Neurosurg 84:785-791, 1996

20. Poiseuille JLM: Recherches experimentales sur le mouvement des liquides dans les tubes de tres petits diametres. Memoires des savants etrangers 9:433-544, 1846
21. Powers WJ, Clarke WR, Grubb RL Jr, Videen TO, Adams HP Jr, Derdeyn CP : Extracranial-intracranial bypass surgery for stroke prevention in hemodynamic cerebral ischemia: the Carotid Occlusion Surgery Study randomized trial. JAMA 306:1983-1992, 2011 (Erratum in JAMA 306:2672, 2011)

22. Regli L, Piepgras DG, Hansen KK: Late patency of long saphenous vein bypass grafts to the anterior and posterior cerebral circulation. J Neurosurg 83:806-811, 1995

23. Sanai N, Zador Z, Lawton MT: Bypass surgery for complex brain aneurysms: an assessment of intracranial-intracranial bypass. Neurosurgery 65:670-683, 2009

24. Schick U, Zimmermann M, Stolke D: Long-term evaluation of EC-IC bypass patency. Acta Neurochir (Wien) 138:938943, 1996

25. Sekhar LN, Bucur SD, Bank WO, Wright DC: Venous and arterial bypass grafts for difficult tumors, aneurysms, and occlusive vascular lesions: evolution of surgical treatment and improved graft results. Neurosurgery 44:1207-1224, 1999

26. Sekhar LN, Duff JM, Kalavakonda C, Olding M: Cerebral revascularization using radial artery grafts for the treatment of complex intracranial aneurysms: techniques and outcomes for 17 patients. Neurosurgery 49:646-659, 2001

27. Sekhar LN, Natarajan SK, Ellenbogen RG, Ghodke B: Cerebral revascularization for ischemia, aneurysms, and cranial base tumors. Neurosurgery 62 (6 Suppl 3):1373-1410, 2008

28. van Swieten JC, Koudstaal PJ, Visser MC, Schouten HJ, van Gijn J: Interobserver agreement for the assessment of handicap in stroke patients. Stroke 19:604-607, 1988

29. von Elm E, Altman DG, Egger M, Pocock SJ, Gøtzsche PC, Vandenbroucke JP : The Strengthening the Reporting of Observational Studies in Epidemiology (STROBE) statement: guidelines for reporting observational studies. Lancet 370:1453-1457, 2007

30. Weiller C, Ringelstein EB, Reiche W, Buell U: Clinical and hemodynamic aspects of low-flow infarcts. Stroke 22:11171123,1991

\section{Disclosures}

The authors report no conflict of interest concerning the materials or methods used in this study or the findings specified in this paper.

\section{Author Contributions}

Conception and design: Matsukawa, Tanikawa, Kamiyama. Acquisition of data: Matsukawa, Tanikawa, Tsuboi, Noda, Ota, Miyata, Oda. Analysis and interpretation of data: Matsukawa. Drafting the article: Matsukawa. Critically revising the article: Matsukawa, Tanikawa. Reviewed submitted version of manuscript: Matsukawa, Tanikawa, Kamiyama, Tsuboi, Noda, Ota, Miyata. Approved the final version of the manuscript on behalf of all authors: Matsukawa. Statistical analysis: Matsukawa. Administrative/technical/material support: Tanikawa, Kamiyama, Tsuboi, Noda, Ota, Miyata, Takeda, Tokuda, Kamada. Study supervision: Tanikawa, Kamiyama, Tsuboi, Takeda, Tokuda, Oda, Kamada.

\section{Correspondence}

Hidetoshi Matsukawa, Department of Neurosurgery, Teishinkai Hospital, 1-6, Higashi 8, Kita 44, Higashi-ku, Sapporo, 007-0844 Hokkaido, Japan.email: nowornever1982@gmail.com. 